Abstracta Iranica Abstranica

Revue bibliographique pour le domaine irano-aryen

Volume 32-33 | 2013

Comptes rendus des publications de 2009-2010

\title{
Mansour Bonakdarian. Erin and Iran Resurgent: Irish Nationalists and the Iranian Constitutional Revolution
}

\section{Denis Hermann}

\section{(2) OpenEdition \\ 1 Journals}

\section{Édition électronique}

URL : http://journals.openedition.org/abstractairanica/40765

DOI : 10.4000/abstractairanica.40765

ISSN : 1961-960X

Éditeur :

CNRS (UMR 7528 Mondes iraniens et indiens), Éditions de l'IFRI

\section{Édition imprimée}

Date de publication : 1 décembre 2013

ISSN : 0240-8910

\section{Référence électronique}

Denis Hermann, « Mansour Bonakdarian. Erin and Iran Resurgent: Irish Nationalists and the Iranian Constitutional Revolution », Abstracta Iranica [En ligne], Volume 32-33 | 2013, document 287, mis en ligne le 01 juillet 2016, consulté le 27 septembre 2020. URL : http://journals.openedition.org/ abstractairanica/40765; DOI : https://doi.org/10.4000/abstractairanica.40765

Ce document a été généré automatiquement le 27 septembre 2020.

Tous droits réservés 


\section{Mansour Bonakdarian. Erin and Iran Resurgent: Irish Nationalists and the Iranian Constitutional Revolution}

Denis Hermann 


\section{RÉFÉRENCE}

Mansour Bonakdarian. « Erin and Iran Resurgent: Irish Nationalists and the Iranian Constitutional Revolution ", in : Houchang E. Chehabi \& Vanessa Martin, eds., The Iranian Constitutional Revolution. Londres, I.B. Tauris, 2010, p. 291-218.

Cet article de Mansour Bonakdarian s'ajoute à une liste de publications déjà très importante et de grande qualité sur les relations entre l'Iran et les îles britanniques, le Royaume-Uni en particulier. Dans cette étude très aboutie, l'A. analyse les liens de solidarité entre certains militants nationalistes irlandais et les pro-constitutionnalistes iraniens. Il revient ainsi en détail sur le discours de plusieurs politiciens irlandais à ce sujet, ceux du IPP (Irish Home Rule party), du IRB (Irish Republican Brotherhood) ou du Sinn Féin. Les pro-constitutionnalistes iraniens, comme les nationalistes indiens ou égyptiens, étaient perçus par certains nationalistes irlandais comme des frères d'armes dans la lutte contre l'impérialisme britannique. Cet intérêt s'accrut considérablement après la conclusion du pacte anglo-russe du 31 août 1907. Mansour Bonakdarian examine également la perception de l'Iran dans l'imaginaire des nationalistes irlandais. Certains militants ou intellectuels irlandais sont allés jusqu'à développer des théories raciales présentant les Irlandais comme les premiers aryens du Royaume-Uni, la culture gaélique ayant transmis la « civilisation » aux îles britanniques avant l'occupation de l'Irlande par les Anglais. Enfin, l'A. relève les différents facteurs qui expliquent le désintérêt des Iraniens pour la cause irlandaise.

\section{AUTEURS}

\section{DENIS HERMANN}

CNRS, Mondes iranien et indien, Paris 